\title{
Maternal and Perinatal Outcome in Gestational Diabetes Mellitus Compared to Pregestational Diabetes Mellitus
}

\author{
Mustary Fa, Chowdhury $\mathrm{TA}^{\mathrm{b}}$, Begum $\mathrm{F}^{\mathrm{c}}$, Mahjabeen $\mathrm{N}^{\mathrm{d}}$
}

\begin{abstract}
Background: Diabetes mellitus is the most frequently encountered endocrine disorder in pregnancy and is associated with adverse outcomes if remain undiagnosed or untreated.

This study was done to compare the maternal and perinatal outcome of pregestational diabetes mellitus (PGDM) with that of gestational diabetes (GDM).

Methods: This observational analytical study with group comparison was carried out in the Department of Obstetrics and Gynaecology, BIRDEM General Hospital, Dhaka from July 2015 to June 2016. This study was conducted on two groups of pregnant women: group A (PGDM) and group B (GDM). A total of 100 cases were selected and in each group 50 pregnant women were enrolled. Singleton pregnancy and age 18 to 45 years were included. Pregnancy with hypertension, heart disease, renal disease and other metabolic disorders were excluded.

Results: In this study mean gestational age of the study subjects were $35.72 \pm 2.61$ weeks and $36.58 \pm 2.34$ weeks in PGDM and GDM groups. History of GDM [34.0\% vs 16.0\%], intrauterine death (IUD) [14.0\% vs $2.0 \%]$ and abortion [22.0\% vas $6.0 \%$ ] were significantly higher among PGDM patients than GDM patients. Regarding present pregnancy complications, polyhydramnios $[32.0 \% \mathrm{vs} 14.0 \%]$, preterm delivery $[38.0 \% \mathrm{vs}$ $20.0 \%]$, vulvovaginitis [28.0\% vs $12.0 \%$ ] and premature rupture of membrane (PROM) [24.0\% vs $8.0 \%$ ] were significantly higher in PGDM than GDM patients. Wound infection was significantly high in PGDM groups [35.7\% vs 11.1\%] among the patients delivered by lower uterine Cesarean section (LUCS). Regarding perinatal complications, hypoglycemia [22.0\% vs 8.0\%], birth asphyxia [24.0\% vs 8.0\%], RDS [24.0\% vs 8.0\%] were significantly higher among PGDM comparing GDM patients.
\end{abstract}

Conclusion: The maternal and perinatal outcomes of pregestational diabetes mellitus were less favorable than those of gestational diabetes mellitus.

Key Words : Gestational diabetes mellitus, pregestational diabetes, maternal outcome, perinatal outcome.

(BIRDEM Med J 2019; 9(2): 127-132)

\section{Author Information}

a. Dr. Faryal Mustary, Associate Consultant, NHN, Rampura Centre, Diabetic Association of Bangladesh.

b. Professor Dr. T.A. Chowdhury, Professor, Department of Obstetrics and Gynaecology, BIRDEM General Hospital, Dhaka.

c. Professor Dr. Ferdousi Begum, Professor and Head of the Department of Obstetrics and Gynaecology, BIRDEM General Hospital, Dhaka.

d. Nusrat Mahjabeen, Lecturer, Department of Obstetrics and Gynaecology, Z.H. Sikder Women's Medical College and Hospital, Dhaka.

Address of correspondence: Dr. Faryal Mustary, Associate Consultant, NHN, Rampura Centre, Diabetic Association of Bangladesh. E-mail: dr.faryalsaroare@gmail.com

Received: June 9, 2018

Accepted: February 28, 2019

\section{Introduction}

Diabetes mellitus is a chronic condition characterized by increased glucose levels in the body. The long-term increased levels of glucose, called hyperglycemia, result in various health complications. ${ }^{1,2}$ When diabetes mellitus is diagnosed before pregnancy, it is designated as pre-gestational diabetes mellitus (PGDM).

Gestational diabetes mellitus (GDM) is defined as a glucose intolerance of variable severity with onset or first recognized during the present pregnancy. The entity usually presents late in the second or during the third trimester. ${ }^{3}$ It is one of the most common medical complications of pregnancy. ${ }^{4}$ GDM can adversely 
impact perinatal outcome, increase the risk of obesity in offspring and the subsequent development of diabetes in mothers. ${ }^{5,6}$ Prevalence of GDM is $9.7 \%$ according to the WHO criteria and $12.9 \%$ according to the ADA criteria in Bangladesh. ${ }^{7}$ South Asians are more prone to have diabetes at an earlier age and thus more vulnerable to GDM. ${ }^{8}$

Pregnancy is a great stressful physiological condition in women during their reproductive period. Hyperglycemia at the time of conception and in early pregnancy specially during organogenesis results in six fold increase in risk of midline defects in the developing embryo. ${ }^{3}$ Even a mild increase in glucose levels during pregnancy can adversely affect both the mother and fetus. Increased incidences of pre-eclampsia, preterm delivery, miscarriage, fetal malformation and perinatal mortality and morbidity have been reported in diabetic pregnancies in comparison to the general population. ${ }^{9}$ Hyperglycaemia during pregnancy is associated with macrosomia, which may subsequently lead to shoulder dystocia and birth trauma in addition to an increase in the rate of Caesarean sections. ${ }^{10}$

Globally, researchers are concerned about an increase in the prevalence of gestational diabetes mellitus (GDM) and pregestational diabetes (PGDM). ${ }^{11}$ Middle Eastern countries are reported to have a high prevalence of GDM and PGDM, ranging from $4.7 \%$ in $\operatorname{Iran}^{12}$ to $24.9 \%$ in the United Arab Emirates ${ }^{13}$ in comparison to the United States, where the prevalence ranges from $3.47 \%$ to $7.15 \% .{ }^{14} \mathrm{PGDM}$ and GDM are associated with adverse fetal and maternal outcomes. ${ }^{15}$ Adverse fetal outcomes include congenital anomalies, trauma during birth, macrosomia and perinatal mortality. ${ }^{16}$ Adverse maternal outcomes include increased rates of caesarean section and increased lifetime risk of developing type 2 diabetes. ${ }^{17}$ Cesarean deliveries may be associated with a range of morbidities, with complications ranging from mild to serious. ${ }^{18}$ Pregnant diabetic women have an increased risk of developing obstetric complications such as preeclampsia and preterm delivery and perinatal complications such as miscarriages and fetal malformations. These complications are observed more frequently in women with PGDM compared to women with GDM; this may be due to the prolonged and severe fetal exposure to hyperglycaemia. ${ }^{19}$

Number of studies on this subject done in our country is limited. So the present study is planned to find out the maternal and perinatal outcome of pregnancy among patients with pregestational diabetes and gestational diabetes mellitus.

\section{Methods}

This observational analysitcal study was carried out in the Department of Obstetrics and Gynaecology in BIRDEM hospital, Dhaka, from July 2015 to June 2016 over a period of one year. Study was carried out between two groups of pregnant women. Fifty cases of PGDM pregnant women (Group-A) and 50 cases of GDM pregnant women of all trimester were enrolled from the Inpatient Department, Department of Obstetrics and Gynaecology, BIRDEM Hospital, Dhaka in this study. Singleton pregnancy and age 18 to 45 years (mean age $26 \pm$ ) were included. Pregnancy with hypertension, heart disease, renal disease and other metabolic disorders were excluded.

PGDM patients were diagnosed case of diabetes and GDM patients were selected after doing OGTT (diagnosed by diagnostic criteria of NICE Clinical Guideline, February, 2015). Then follow up was done for several times, during antenatal, intrapartum, post partum and perinatal period. The perinatal and postpartum complications were recorded during the period of hospital stay.

The purpose of the study was discussed with the patients who fulfilled the enrollment criteria. Information about the patients was recorded in the prescribed data collection form, after taking informed consent. Data were collected by interview and from records. Statistical analysis was performed by using window based computer software devised with Statistical Packages for Social Sciences (SPSS-21) (SPSS Inc, Chicago, IL, USA). Quantitative data were expressed as mean and standard deviation and qualitative data were expressed as frequency and percentage. Association between categorical variables was analyzed by Chi-square test and continuous variable by independent sample t-test. For all statistical tests, $\mathrm{p}$ value $<0.05$ was considered statistically significant.

\section{Results}

Total patients were 100, 50 in each group. There was no significant difference between group A (PGDM) and group B (GDM) redarding age and gestational age (Table I). Table II shows distribution of study subjects 
according to past obstetric history. Bad past obstetric history was significantly high in PGDM. History of GDM, intrauterine death (IUD) and abortion was significantly high in group A (PGDM) than group B (GDM). There was no significant difference between group A and group B in blood glucose at fasting and at 2-hr ABF (Table III). Table IV shows polyhydramnios, preterm delivery, vulvovaginitis and premature rupture of membrane significantly higher in group A than group B. Mode of delivery was comparable between two groups (Table V). Table VI shows no significant difference in intra-partum maternal complication between two groups as was true for pregnancy outcome (Table VII).

Table I Age and gestational age of the study population at enrollment $(\mathrm{N}=100)$

\begin{tabular}{|c|c|c|c|}
\hline & \multicolumn{2}{|c|}{ Group } & \multirow[t]{2}{*}{$\mathrm{p}$ value } \\
\hline & Group A (Mean \pm SD) & Group B (Mean \pm SD) & \\
\hline Age (years) & $26.62 \pm 4.57$ & $26.04 \pm 4.62$ & 0.529 \\
\hline Gestational age (weeks) & $35.72 \pm 2.61$ & $36.58 \pm 2.34$ & 0.087 \\
\hline \multicolumn{4}{|c|}{ Table II Distribution of study population according to their past obstetric history $(\mathrm{N}=100)$} \\
\hline \multirow[t]{2}{*}{ Past obstetric history } & \multicolumn{2}{|c|}{ Group } & \multirow[t]{2}{*}{$\mathrm{p}$ value } \\
\hline & Group A (n, \%) & Group B (n, \%) & \\
\hline History of GDM & $17(34.0)$ & $8(16.0)$ & 0.038 \\
\hline Congenital anomaly & $6(12.0)$ & $2(4.0)$ & 0.140 \\
\hline IUD & $7(14.0)$ & $1(2.0)$ & 0.027 \\
\hline Over weight baby & $2(4.0)$ & $0(0.0)$ & 0.495 \\
\hline Stillbirth & $1(2.0)$ & $0(0.0)$ & 1.000 \\
\hline Abortion & $11(22.0)$ & $3(6.0)$ & 0.021 \\
\hline
\end{tabular}

*Multiple responses

Table III Distribution of study population according to their mean blood glucose level at enrolment in the study $(\mathrm{N}=100)$

\begin{tabular}{lccc} 
Blood glucose & \multicolumn{2}{c}{ Group } & P value \\
\cline { 2 - 4 } & Group A $($ Mean \pm SD) & Group B (Mean \pm SD) & 0.347 \\
\hline Fasting & $6.68 \pm 1.19$ & $6.47 \pm 1.10$ & 0.219
\end{tabular}

Table IV Distribution of study population according to the complications in current pregnancy $(\mathrm{N}=100)$

\begin{tabular}{lccc} 
Present pregnancy complications & \multicolumn{2}{c}{ Group } & P value \\
\cline { 2 - 3 } & Group A (n, \%) & Group B (n, \%) & \\
\hline Abortion & $3(6.0)$ & $2(4.0)$ & 1.000 \\
UTI & $13(26.0)$ & $15(30.0)$ & 0.656 \\
Polyhydramnios & $16(32.0)$ & $7(14.0)$ & 0.032 \\
Preterm delivery & $19(38.0)$ & $10(20.0)$ & 0.047 \\
PIH/Pre-eclampsia & $7(14.0)$ & $10(20.0)$ & 0.424 \\
Vulvovaginitis & $14(28.0)$ & $6(12.0)$ & 0.046 \\
PROM & $12(24.0)$ & $4(8.0)$ & 0.029 \\
Oligohydramnios & $1(2.0)$ & $0(0.0)$ & 1.000 \\
\hline
\end{tabular}

* Multiple responses 
Table V Distribution of study population according to mode of delivery $(\mathrm{N}=100)$

\begin{tabular}{|c|c|c|c|}
\hline \multirow[t]{2}{*}{ Mode of delivery } & \multicolumn{2}{|c|}{ Group } & \multirow[t]{2}{*}{$P$ value } \\
\hline & Group A (n, \%) & Group B (n, \%) & \\
\hline Vaginal delivery & $22(44.0)$ & $23(46.0)$ & 0.841 \\
\hline Caesarean section & $28(56.0)$ & $27(54.0)$ & \\
\hline
\end{tabular}

Table VI Distribution of study population according to intra-partum maternal complications who delivered vaginally $(\mathrm{N}=100)$

\begin{tabular}{lccc}
$\begin{array}{l}\text { Intra-partum maternal } \\
\text { complications }\end{array}$ & \multicolumn{2}{c}{ Group } & P value \\
\cline { 2 - 4 } & $\begin{array}{c}\text { Group A (n=22) } \\
(\mathrm{n}, \%)\end{array}$ & $\begin{array}{c}\text { Group B (n=23) } \\
(\mathrm{n}, \%)\end{array}$ \\
\hline Cervical tear & $2(9.1)$ & $3(13.0)$ & 0.673 \\
Perineal tear & $2(9.1)$ & $3(13.0)$ & 0.673 \\
Shoulder dystocia & $1(4.5)$ & $2(8.7)$ & 0.577 \\
\hline
\end{tabular}

Table VII Distribution of study population according to their pregnancy outcome (100)

\begin{tabular}{lccc} 
& \multicolumn{2}{c}{ Group } & P value \\
\cline { 2 - 3 } Pregnancy outcome & Group A & Group B & \\
\hline Live birth & $39(78.0)$ & $41(82.0)$ & 0.617 \\
Abortion & $3(6.0)$ & $2(4.0)$ & 1.000 \\
IUFD & $6(12.0)$ & $5(10.0)$ & 0.749 \\
Fresh stillbirth & $2(4.0)$ & $2(4.0)$ & 1.000 \\
\hline
\end{tabular}

There was no significant difference in post-partum maternal complications between group A(PGDM) and group B (GDM) who delivered by LUCS except wound infection (Table VIII). Wound infection was significantly high in PGDM group. No significant difference in post-partum maternal complications between group A (PGDM) and group B (GDM) who delivered by vaginally. There was no significant difference in hypoglycemia, birth asphyxia and RDS between two groups (Table IX). No significant difference regarding congenital malformation between group A and group B was found (Table X).

Table VIII Distribution of study population according to post-partum maternal complications $(\mathrm{N}=100)$

\begin{tabular}{lccc}
$\begin{array}{l}\text { Post-partum maternal } \\
\text { complications }\end{array}$ & $\begin{array}{c}\text { Group } \\
\text { Group A (n=28) } \\
(\mathrm{n}, \%)\end{array}$ & $\begin{array}{c}\text { Group B (n=27) } \\
(\mathrm{n}, \%)\end{array}$ & \\
\hline Delivered by LUCS & $4(14.3)$ & $3(11.1)$ & 1.000 \\
PPH & $6(21.4)$ & $8(29.6)$ & 0.485 \\
UTI & $3(10.7)$ & $2(7.4)$ & 0.670 \\
Mastitis & $10(35.7)$ & $3(11.1)$ & 0.032 \\
Wound infection & $1(3.6)$ & $1(3.7)$ & 1.000 \\
Others & & & 0.346 \\
Delivered vaginally & $3(13.6)$ & $1(4.3)$ & 1.000 \\
PPH & $2(9.1)$ & $3(13.0)$ & \\
UTI & & &
\end{tabular}

Multiple responses 
Table IX Distribution of study population according to perinatal complications ( $\mathrm{N}=100)$

\begin{tabular}{lccc}
\hline Perinatal complications & \multicolumn{2}{c}{ Group } & P value \\
\cline { 2 - 3 } & Group A & Group B & \\
\hline Hypoglycemia & $11(22.0)$ & $4(8.0)$ & 0.049 \\
Birth asphyxia & $12(24.0)$ & $4(8.0)$ & 0.029 \\
Hyperbilirubinemia & $8(16.0)$ & $6(12.0)$ & 0.564 \\
Macrosomia & $1(2.0)$ & $4(8.0)$ & 0.169 \\
RDS & $12(24.0)$ & $4(8.0)$ & 0.029 \\
Congenital malformation & $4(8.0)$ & $1(2.0)$ & 0.362 \\
\hline
\end{tabular}

* Multiple responses

Table X Distribution of study population according to congenital malformation $(\mathrm{N}=100)$

\begin{tabular}{lccc} 
Type of congenital malformation & \multicolumn{2}{c}{ Group } & P value \\
\cline { 2 - 3 } & Group A & Group B & \\
\hline Present & $4(8.0)$ & $1(2.0)$ & 0.362 \\
\hline
\end{tabular}

\section{Discussion}

In this study, there was no significant difference between PGDM and GMD regarding mean age of the study subjects. Maternal age was higher in PGDM than that of GDM in the study of Wahabi et al. ${ }^{20}$ which is similar to this study. In a study of Clausen et al. ${ }^{21}$ shows that increasing age of the patients of GDM had been described as a risk factor for pregnancy complication.

There was statistical significant difference between PGDM and GDM in past bad obstetric history. History of GDM, IUD and abortion were significantly higher among PGDM patients than GDM patients. History of previous miscarriage was higher in PGDM than GDM. ${ }^{20}$

Regarding present pregnancy complications, polyhydramnios, preterm delivery, vulvovaginitis and PROM were significantly higher in PGDM than GDM patients. In PGDM group 1 patient had oligohydramnios. Women with PGDM had a significantly higher incidence preterm deliveries comparing GDM. ${ }^{20,22}$ Incidence of Oligohydramnios was also higher in PGDM comparing GDM. ${ }^{22}$

Caesarean section was more frequently needed in pregestational than gestation pregnant women. There was no statistical significant difference between PGDM and GMD. Wahabi et al. ${ }^{20}$ revealed $\mathrm{C} / \mathrm{S}$ was higher in PGDM than GDM.
Pregnancy outcome was less favourable in PGDM than GDM. The patients of PGDM lost 11 pregnancy and the patients of GDM lost 9 pregnancy; as stillbirth, IUFD and abortion. The still birth rate was higher in PGDM than GDM. ${ }^{20}$

Regarding perinatal complications hypoglycemia, birth asphyxia and RDS were significantly higher in PGDM than GDM group, which is similar to the study of AbuHeija et al. ${ }^{22}$, they found neonatal hypoglycemia were significantly high in PGDM. Macrosomia has been demonstrated to be the predominant adverse outcome in cases of GDM. ${ }^{23}$

In this study, less significant difference were found bewteen PGDM and GDM outcome. It may be mentionable that the study was done in a referral hospital, where the diabetic patients were well managed. So it is believed that, if the field of study was any where rather than referral hospital, the result of the same study would become remarkably different and significant.

\section{Conclusion}

The maternal and perinatal outcomes of pregestational diabetes mellitus were less favorable than those of gestational diabetes mellitus.

Conflict of interest: Nothing to declare. 


\section{References}

1. International Diabetes Federation. (2011). What is Diabetes? Retrieved on June 14, 2016, from http://www.idf.org/node/ 23928

2. Maraschin JF. Classification of diabetes. Adv Exp Med Biol 2011; 771: 12-19.

3. Janjen C, Greenspoon JS, Palmer SM. Diabetes Mellitus and pregnancy. In: DeChemey AH, Nathan L, editors. Current Obstetric and Gynecologic Diagnosis and Treatment. USA: McGraw Hill. 2003; 315-325.

4. American Diabetes Association. Diagnosis and classification of diabetes mellitus. Diabetes Care 2013; 36: S67-74.

5. Sullivan SD, Umans JG, Ratner R. Gestational diabetes: implications for cardiovascular health. Current Diabetes Reports 2012;12(1):43-52.

6. Krishnaveni GV, Veena SR, Hill JC, Kehoe S, Karat SC, Fall $\mathrm{CH}$. Intrauterine exposure to maternal diabetes is associated with higher adiposity and insulin resistance and clustering of cardiovascular risk markers in Indian children. Diabetes Care 2010;33(2):402-4.

7. Jesmin S, Akter S, Akashi H, Al-Mamun A, Rahman MA, Islam MM, et al. Screening for gestational diabetes mellitus and its prevalence in Bangladesh. Diabetes Research and Clinical Practice 2014;103(1):57-62.

8. Gujral UP, Pradeepa R, Weber MB, Narayan KM, Mohan V. Type 2 diabetes in South Asians: similarities and differences with white Caucasian and other populations. Annals of the New York Academy of Sciences 2013;1281(1):51-63.

9. Balaji V, Seshiah V. Management of diabetes in pregnancy. J Assoc Physicians India 2011;59(Suppl):33-36.

10. Poolsup N, Suksomboon N, Amin M. Effect of treatment of gestational diabetes mellitus: a systematic review and metaanalysis. PloS One 2014;9(3):e92485.

11. Carolan M, Davey MA, Biro MA, Kealy M. Maternal age, ethnicity and gestational diabetes mellitus. Midwifery 2012;28(6):778-83.

12. Hossein-Nezhad A, Maghbooli Z, Vassigh AR, Larijani B. Prevalence of gestational diabetes mellitus and pregnancy outcomes in Iranian women. Taiwanese Journal of Obstetrics and Gynecology 2007;46(3):236-41.
13. Agarwal MM, Dhatt GS, Shah SM. Gestational diabetes mellitus: simplifying the international association of diabetes and pregnancy diagnostic algorithm using fasting plasma glucose. Diabetes Care 2010;33(9):2018-20.

14. Bardenheier BH, Elixhauser A, Imperatore G, Devlin HM, Kuklina EV, Geiss LS, et al. Variation in prevalence of gestational diabetes mellitus among hospital discharges for obstetric delivery across 23 states in the United States. Diabetes Care 2013;36(5):1209-14.

15. Crowther CA, Hiller JE, Moss JR, McPhee AJ, Jeffries WS, Robinson JS. Effect of treatment of gestational diabetes mellitus on pregnancy outcomes. New England Journal of Medicine 2005;352(24):2477-86.

16. Ayaz A, Saeed S, Farooq MU, Bahoo A, Luqman M, Hanif K. Gestational diabetes mellitus diagnosed in different periods of gestation and neonatal outcome. Dicle Medical Journal/ Dicle Tip Dergisi 2009;36(4): 235-40.

17. Bellamy L, Casas JP, Hingorani AD, Williams D. Type 2 diabetes mellitus after gestational diabetes: a systematic review and meta-analysis. Lancet 2009;373(9677):1773-79.

18. Silver RM, Landon MB, Rouse DJ, Leveno KJ, Spong CY, Thom EA, et al. Maternal morbidity associated with multiple repeat cesarean deliveries. Obstetrics \& Gynecology 2006;107(6):1226-32.

19. Sugiyama T, Saito M, Nishigori H, Nagase S, Yaegashi N, Sagawa N, et al. Comparison of pregnancy outcomes between women with gestational diabetes and overt diabetes first diagnosed in pregnancy: a retrospective multi-institutional study in Japan. Diabetes Research and Clinical Practice 2014;103(1):20-25.

20. Wahabi HA, Fayed A, Esmaeil SA. Maternal and Perinatal Outcomes of Pregnancies Complicated with Pre-gestational and Gestational Diabetes Mellitus in Saudi Arabia. J Diabetes Metab 2014;5(399):2.

21. Clausen TD, Mathiesen E, Ekbom P, Hellmuth E, MandrupPoulsen T, Damm P. Poor pregnancy outcome in women with type 2 diabetes. Diabetes Care 2005;28(2):323-28.

22. Abu-Heija AT, Al-Bash M, Mathew M. Gestational and Pregestational Diabetes Mellitus in Omani Women: Comparison of obstetric and perinatal outcomes. Sultan Qaboos University Medical Journal 2015;15(4):e496.

23. Mitanchez D. Foetal and neonatal complications in gestational diabetes: perinatal mortality, congenital malformations, macrosomia, shoulder dystocia, birth injuries, neonatal complications. Diabetes \& Metabolism 2010;36(6):617-27. 